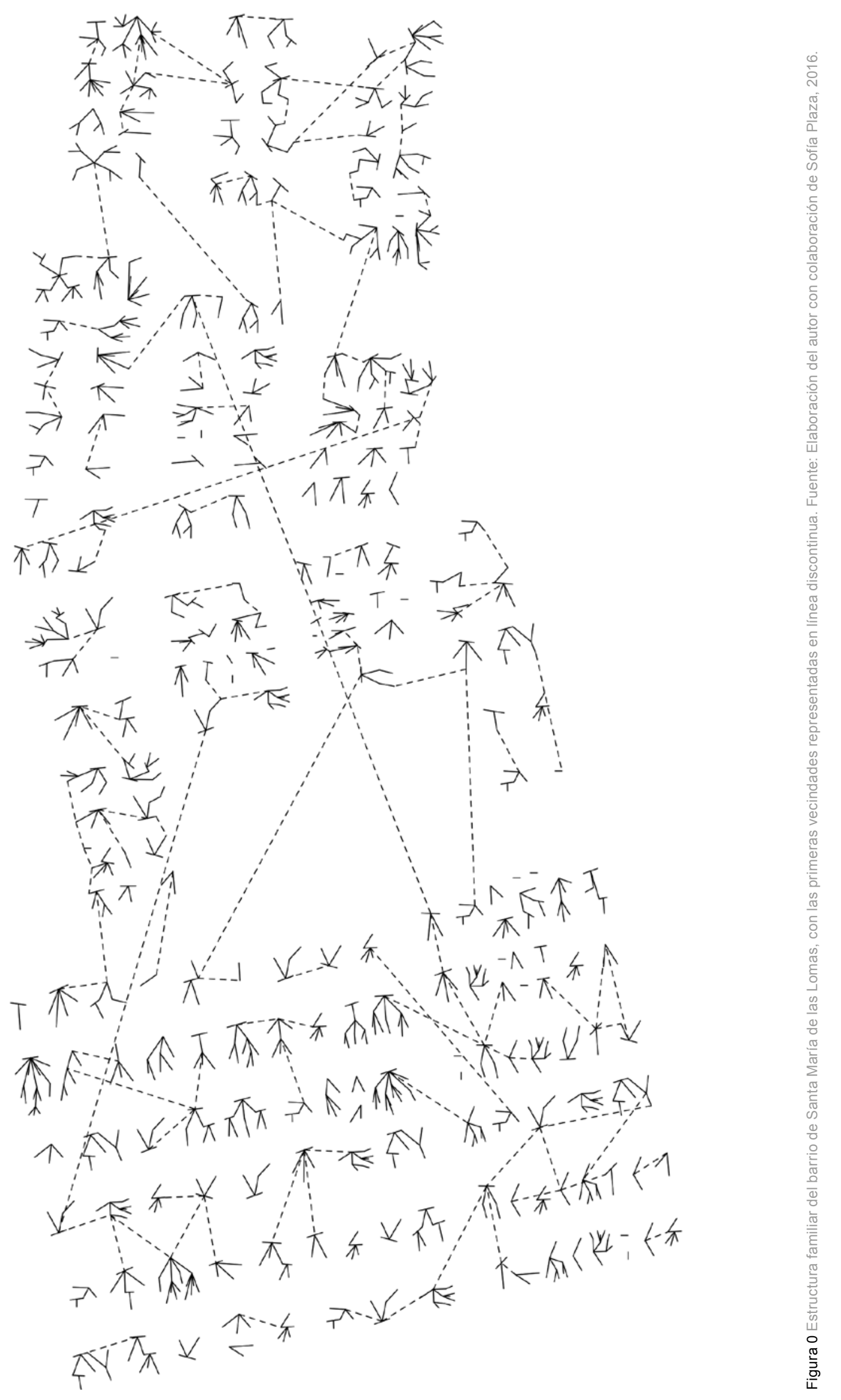



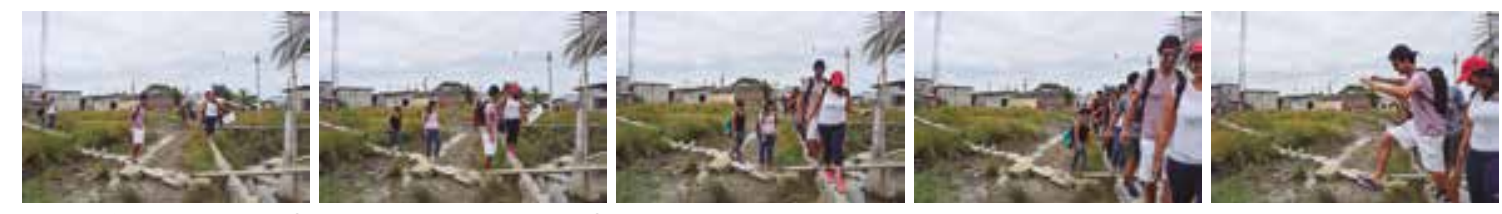

\title{
TRANSFORMACIONES INCREMENTALES EN LA VIVIENDA INFORMAL CONSOLIDADA: EL CASO DE SANTA MARÍA DE LAS LOMAS, GUAYAQUIL'
}

\author{
INCREMENTAL TRANSFORMATIONS IN CONSOLIDATED INFORMAL HOUSING: \\ THE CASE OF SANTA MARÍA DE LAS LOMAS, GUAYAQUIL'
}

Ignacio de Teresa Fernández-Casas²

RESUMEN

La máxima repercusión que puede tener un proyecto arquitectónico en la transformación social de un barrio no es cambiar la sociedad mediante el proyecto, sino permitir que la sociedad cambie a través de la arquitectura. En el caso de la vivienda informal, esta transformación se produce mediante pequeñas alteraciones incrementales en cada vivienda, clasificadas en tres tipos: improvisaciones, tanteos y aproximaciones. Éstas dan lugar a comportamientos globales lógicos que pueden suponer avances significativos en la estructura social de un barrio.

El presente artículo expone el avance parcial de la investigación llevada a cabo en la Universidad Católica de Santiago de Guayaquil, cuyo objetivo consiste en encontrar influencias mutuas entre las transformaciones físicas de la casa y las transformaciones sociales de la familia, en el barrio informal de Santa María de las Lomas, de Guayaquil. Para ello, se generan diagramas comparativos entre ambos motores de transformación, los cuales describen un detonante de cambio que no es ni la arquitectura ni la sociedad, sino la relación dialéctica entre ambas.

Palabras clave: familia, transformación social, necesidad de vivienda, viviendas agrupadas, tipologías.

\section{ABSTRACT}

The maximum impact that an architectural project can have in the social transformation of a neighborhood is not to change society through the project, but to make it possible for society to change through architecture. In the case of informal housing, this transformation occurs through small, incremental changes in each dwelling. These can be classified into three types: improvised, trial and error, and approximations, which give rise to logical global behaviors that can mean significant advances in the social structure of the neighborhood.

This article presents progress of research carried out at the Catholic University of Santiago de Guayaquil, which seeks to find mutual influences between the physical transformations of the house, and the social transformation of the family in the informal neighborhood of Santa María de las Lomas, in Guayaquil. To this end, comparative diagrams of both transformation systems are produced, which describe a trigger for change that is neither architecture nor society, but rather a dialectic relationship between the two.

Keywords: family, social transformation, housing need, grouped dwellings, typologies.

[1] Articulo basado en los resultados del proyecto de investigación "Relación entre las características tipológicas funcionales de la vivienda unifamiliar informal y su evolución espacial: caso barrio Santa María de las Lomas, Guayaquil”, código SIU-871, patrocinado por SINDE (Sistema de Investigación y Desarrollo) de la Universidad Católica de Santiago de Guayaquil, años: 2013-2014

[2] Departamento de Proyectos de la Universidad Católica de Santiago de Guayaquil, Ecuador. jose.deteresa@ucsg.edu.ec 
Bajo la cultura del "big-bang" arquitectónico, como acción puntual y aislada capaz de producir grandes transformaciones en la sociedad, subyacen los microproyectos silenciosos de vivienda que dan forma al principal motor de cambio social. Junto al Pompidou de París o el museo de arte de Sao Paulo, la arquitectura menuda de las transformaciones de vivienda es la responsable de los cambios sociales más naturales de un sistema urbano. De igual manera, los grandes acontecimientos capaces de transformar significativamente una sociedad -crisis económicas, guerras, revoluciones, etc.- se superponen a un complejo y silencioso sistema de pequeñas transformaciones sociales que evolucionan de forma ininterrumpida. Estas transformaciones no son consecuencia de un momento de crisis puntual, sino del estado de "crisis" permanente en el que se encuentran las ciudades en desarrollo como Guayaquil, en las que las mutaciones más profundas y naturales de la sociedad suceden probablemente en el ámbito de lo doméstico, como suma de pequeños detonantes de cambio producidos por la familia, como base de la sociedad, y no como consecuencia de grandes proyectos arquitectónicos aislados.

\section{LA VIVIENDA INFORMAL CONSOLIDADA}

El concepto de "consolidación" en el ámbito social, y específicamente en relación a una estructura familiar, significa el afianzamiento de su estructura social, lo que conlleva la proliferación de la familia a través del aumento de sus núcleos familiares: los hijos de la primera familia se establecen en la casa con sus respectivas familias, junto a posibles familiares cercanos como primos, etc. Es decir, la consolidación favorece la evolución y el cambio de la familia, por lo que "consolidar" es aquí sinónimo de "transformar". $3 \mathrm{~W}$

Sin embargo, en el ámbito arquitectónico la consolidación de un tejido urbano suele ir asociada a lo contrario. Las casas, al consolidarse, normalmente encuentran un estado final y suficientemente "acabado" como para no necesitar transformarse más. La consolidación implica el agarrotamiento y cese de las transformaciones físicas de la vivienda, mientras que en la familia, dicha consolidación conlleva el aumento de las transformaciones sociales, lo cual crea un desajuste entre casa y familia, cuya única solución es el traslado; situación que genera sistemas urbanos basados en el alquiler.

Por el contrario, la arquitectura informal consolidada es un caso especial en el que existe una estrecha relación entre la casa y la familia, cuyos desarrollos se producen habitualmente en paralelo, por lo que la consolidación de la casa implica, paradójicamente, su transformación

[3] En el campo de la informática, la consolidación de un producto también implica su cambio constante, como por ejemplo en los sistemas operativos de un ordenador. En su texto "El futuro no es futurible", el grupo Zuloark compara la arquitectura adaptable que requiere la sociedad, con los sistemas informáticos y sus actualizaciones de software, sugiriendo que la arquitectura pueda tener también versiones sucesivas de un mismo producto $(2.0,2.1 \ldots)$. 


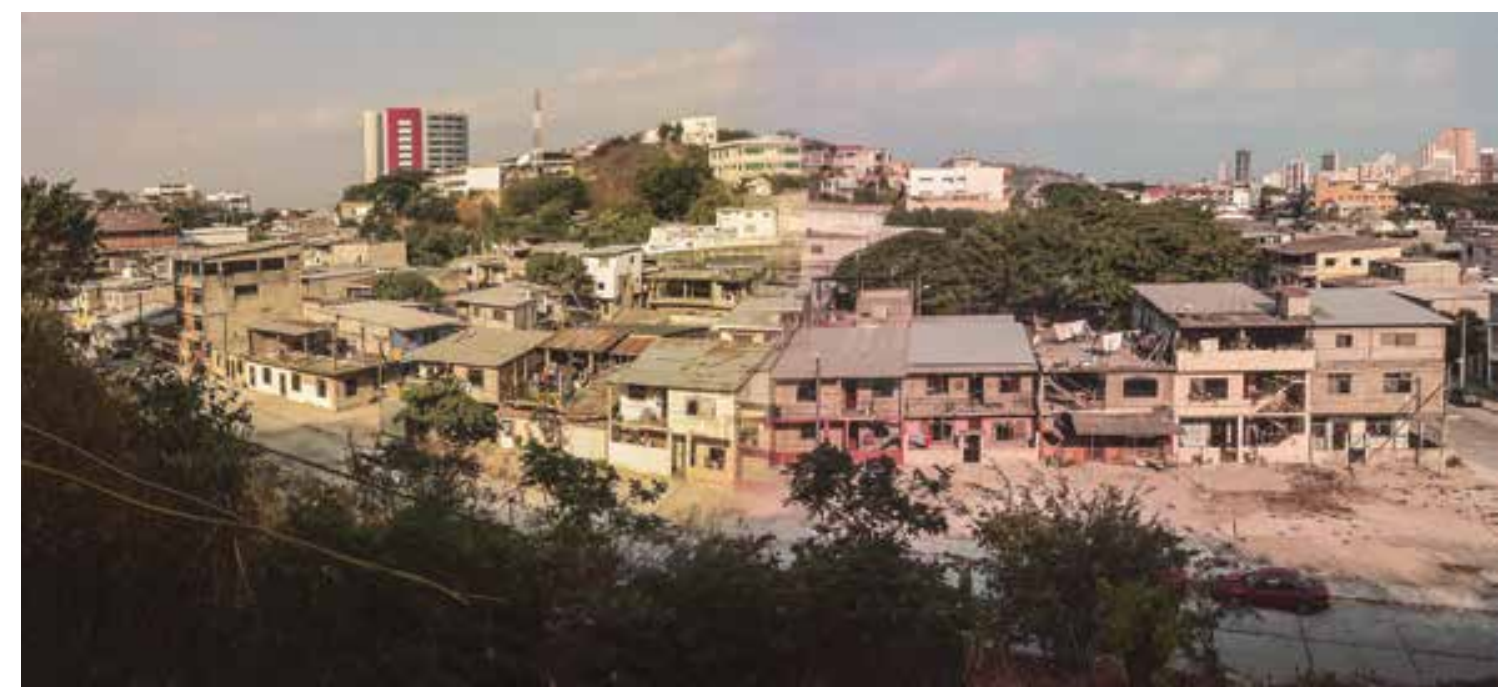

Figura 1 Vista de Santa María de las Lomas desde la Universidad Católica de Santiago de Guayaquil. Fuente: Fotografía del autor, 2014

constante. De esta forma, la casa se convierte en una plataforma mutable en la que es capaz de arraigarse la familia como estructura social compleja. Arquitectura y usuario vuelven a tener influencia mutua, de manera que la responsabilidad de crear un hábitat de calidad no recae únicamente en el arquitecto, como orientador de modos de vida a través de su obra, sino también sobre el usuario, cuyas acciones no tienen repercusión solamente en su entorno inmediato, sino además en el sistema urbano global.

El presente trabajo explora la influencia que aparece entre las transformaciones físicas de la casa y las transformaciones sociales de la familia que la ocupa ${ }^{4}$, así como la capacidad de la casa, como mínimo común múltiplo de los tejidos informales de vivienda, de crear un sistema urbano complejo a partir de la suma de decisiones particulares tomadas a escalas inferiores ${ }^{5}$. Para ello se han analizado las transformaciones físicas de las viviendas y las transformaciones sociales de las familias, a escala de casa y de barrio, y de familia y comunidad. Se realizó con este propósito una recogida de información de todas las casas, mediante entrevistas y tomas de datos, que ha permitido mapear comparativamente estas transformaciones incrementales desde la creación del barrio hasta la actualidad.
El artículo ha sido redactado como resultado de la investigación llevada a cabo en la Universidad Católica de Santiago de Guayaquil, sobre vivienda informal consolidada en el barrio de Santa María de las Lomas de Guayaquil, junto al desarrollo personal de la tesis doctoral en la Universidad de Granada. El barrio tiene unas 190 viviendas, con una media de 1,4 núcleos familiares por vivienda, lo que implica un total de alrededor de 270 núcleos familiares en el 2016 (De Teresa, 2015: 11-15). Fue construido a partir de 1960, a raíz del boom cacaotero que propició el aumento de los asentamientos informales, y actualmente está situado en el centro geográfico de la ciudad, encerrado entre la Universidad Católica de Santiago de Guayaquil, la concurrida Avenida Barcelona, una loma, y la ciudadela formal amurallada de La Fuente. Como consecuencia de su enclaustramiento urbano, ha conservado, como muchas otras ciudadelas informales de Guayaquil, las características rurales que tenía en sus inicios en los que acogió familias acostumbradas a la vida en el campo (Figura 1). A pesar de su localización céntrica en la ciudad, ha crecido al margen de la expansión de la trama urbana ortogonal, siguiendo un desarrollo informal con mecanismos de crecimiento rurales que prescinden de la normativa aplicable en el sector. Funciona así como un pueblo encerrado en el centro de la

[4] El estudio de las transformaciones de la casa se apoya en las teorías evolucionistas clásicas de Lamarck y Darwin, cuya influencia condujo a la formulación de la teoría de las transformaciones de D’Arcy Thomson, y que actualmente están siendo revisadas como aplicación al campo de la arquitectura por estudios como Zuloark, entre otros. Las transformaciones sociales en relación a la arquitectura se basan, por su parte, en las teorías antropológicas, que igualmente influencian el panorama arquitectónico contemporáneo, con el trabajo de Caroline Moser como principal aportación a la presente investigación por sus estudios de campo llevados a cabo en la ciudad de Guayaquil en la segunda mitad del siglo XX

[5] El barrio, entendido como sistema emergente, en donde el detonante de las transformaciones globales está a niveles inferiores de organización, coincide con la teoría desarrollada en el campo de la dinámica de sistemas por Willensky y Resnick que, entre otros, ha influenciado a autores como Steven Johnson en su libro "Sistemas emergentes: o qué tienen en común las hormigas, las ciudades y el hardware", aproximándose al campo disciplinar de la arquitectura. Este enfoque heterogéneo es complementado desde otras áreas que se acercan transversalmente al estudio de la ciudad, con autores como Cecil Balmond, desde la ingeniería, o Gilles Clément, desde la jardinería. Ya en el ámbito arquitectónico propiamente, Rem Koolhaas, Stephen Al o Salvador Rueda han abordado el análisis de los sistemas urbanos complejos informales desde el punto de vista de los sistemas emergentes. 


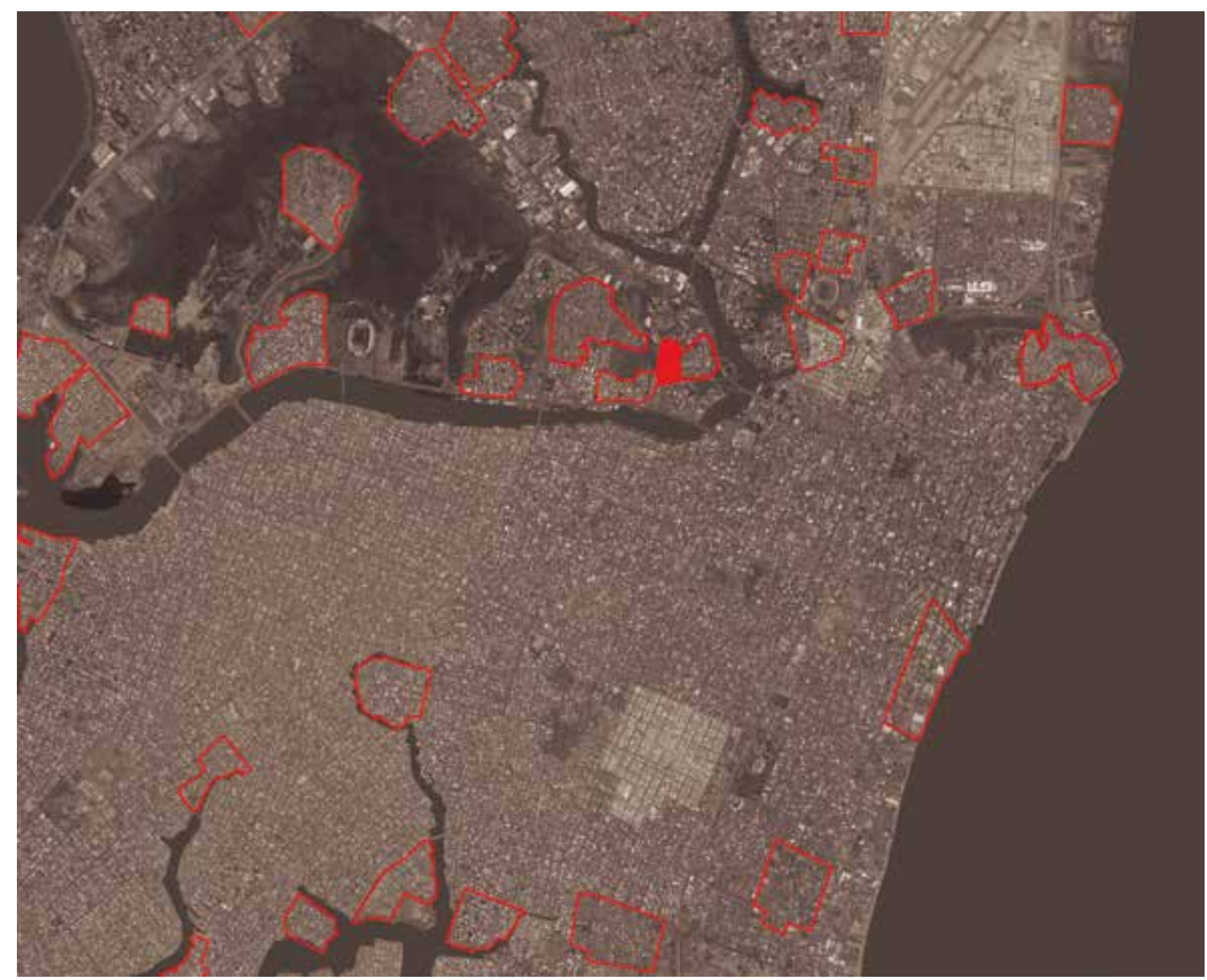

Figura 2 Pueblos en la ciudad: barrios de vivienda informal consolidada en el centro de Guayaquil. Santa María de las Lomas en la parte central, en rojo sombreado. Fuente: Elaboración del autor, 2015

ciudad, y sirve como caso de estudio de las decenas de "poblados" urbanos de Guayaquil y de las ciudades con características similares en todo el mundo ${ }^{6}$ (Figura 2).

\section{TRANSFORMACIONES INCREMENTALES: IMPROVISACIONES, TANTEOS Y APROXIMACIONES}

Se divide la investigación en tres fases, dando lugar a tres herramientas de análisis: improvisaciones, tanteos y aproximaciones. Las improvisaciones definen las transformaciones físicas de las viviendas. Estas transformaciones han sido, a continuación, consideradas a escala de barrio, en donde las decisiones particulares e inmediatas de cada caso dan lugar a vectores de cambio globales lógicos denominados tanteos, que son susceptibles de alcanzar mayor grado de consciencia que por separado, y que por prueba y error van dando forma al barrio. Como tercer paso, se han comparado las improvisaciones y tanteos físicos de las viviendas, con la estructura familiar del barrio, para analizar los movimientos de aproximación entre ambos, y poder detectar la influencia existente entre arquitectura y sociedad como detonante de cambio conjunto.

Las improvisaciones, tanteos y aproximaciones son analizados desde un punto de vista cuantitativo (para evaluar si crece, se completa, se divide o se reduce), y cualitativo (para analizar cómo lo hace). Con el objetivo de medir cuantitativamente el desarrollo de las familias, se utiliza el valor incremental de sus núcleos familiares (Tabla 1), que permite obtener una estimación del futu-

[6] El libro "Villages in the city: a guide to south China's Informal Settlements" analiza los poblados con características de vida rurales existentes en la trama urbana de las grandes ciudades del sur de China. Guayaquil y otras ciudades sudamericanas tienen características similares pero en un estado de consolidación y desarrollo menor que el caso asiático, lo que sirve como posible prospección del presente caso de estudio. 


\begin{tabular}{|c|c|c|c|c|c|c|c|}
\hline \multirow{2}{*}{$\begin{array}{l}\text { CASO DE } \\
\text { ESTUDIO }\end{array}$} & \multirow{2}{*}{$\begin{array}{l}\text { Año de } \\
\text { Inicio }\end{array}$} & \multicolumn{2}{|c|}{ Inicial } & \multicolumn{2}{|c|}{ Actual } & \multicolumn{2}{|c|}{ Incremento } \\
\hline & & Núcleos & Personas & Núcleos & Personas & Núcleos & Personas \\
\hline \# 01 & 1969 & 1 & 6 & 5 & 17 & 4 & 11 \\
\hline \# 02 & 1998 & 2 & 9 & 3 & 13 & 1 & 4 \\
\hline \# 03 & - & - & - & - & - & - & \\
\hline$\# 04$ & 1995 & 1 & 3 & 1 & 6 & 0 & 3 \\
\hline$\# 05$ & 1960 & 1 & 6 & 2 & 8 & 1 & 2 \\
\hline$\# 06$ & 1989 & 1 & 1 & 2 & 11 & 1 & 10 \\
\hline \# 07 & 1999 & 1 & 4 & 7 & 15 & 6 & 11 \\
\hline$\# 08$ & 1978 & 1 & 2 & 3 & 6 & 2 & 4 \\
\hline \# 09 & - & - & - & - & - & - & \\
\hline$\# 10$ & 1974 & 1 & 2 & 1 & 7 & 0 & 5 \\
\hline \# 11 & 1990 & 1 & 2 & 1 & 6 & 0 & 4 \\
\hline$\# 12$ & 1989 & 1 & 1 & 2 & 11 & 1 & 10 \\
\hline \# 13 & 1984 & 1 & 3 & 3 & 10 & 2 & 7 \\
\hline$\# 14$ & 1994 & 1 & 2 & 2 & 10 & 1 & 8 \\
\hline \# 15 & 1969 & 3 & 13 & 3 & 13 & 0 & 0 \\
\hline$\# 16$ & 1997 & 1 & 5 & 1 & 3 & 0 & -2 \\
\hline \# 17 & 1960 & 1 & 6 & 2 & 12 & 1 & 6 \\
\hline$\# 18$ & - & - & - & - & - & - & \\
\hline \# 19 & 1960 & 1 & 3 & 2 & 18 & 1 & 15 \\
\hline$\# 20$ & 1960 & 1 & 5 & 2 & 9 & 1 & 4 \\
\hline \multirow[t]{2}{*}{ \# 21} & 1993 & 1 & 4 & 1 & 6 & 0 & 2 \\
\hline & & & & & Prom. & 1,4 & 5,8 \\
\hline
\end{tabular}

Tabla 1 Incremento de núcleos familiares por vivienda de los 21 casos de estudio iniciales marcados en el plano. Fuente: Elaboración del autor, 2015

ro crecimiento de la casa. Para analizar, por su parte, la manera en que se produce este desarrollo (cualitativamente), no se identifican tipologías, sino caracteres tipológicos, que representan vectores de transformación, y que pueden, a su vez, ser combinados entre sí. Es decir, no hay tipologías claras, sino una mezcla de líneas de desarrollo, como por ejemplo, el crecimiento vertical de la vivienda o su división en planta.

\section{Improvisaciones}

1 Improvisaciones cuantitativas

En el comienzo de la vivienda informal, todo sucede alternadamente dentro de un espacio homogéneo y des-jerarquizado. Todos los usos de la casa se turnan mediante compartimentaciones improvisadas con cortinas o muebles, para más adelante complejizarse en la línea de las necesidades particulares de la familia. La caja es siempre el inicio de la familia de bajos ingresos, porque permite obtener el máximo espacio con la mínima inversión. ${ }^{8}$

Los mecanismos de aproximación cuantitativos entre casa y familia pueden ser expresados mediante operaciones aritméticas sencillas aplicadas al espacio "caja" de origen:

Adición: se produce un aumento incremental de la casa sin un plan previo. El crecimiento puede ser descrito mediante la fórmula: $[1+1+1+2+1+1 \ldots]$ Este sistema permite la independencia entre las partes de la casa, así

[7] "En los sistemas informales se produce una intensa exploración de lo inmediato" (Balmond, 2002:220), de lo hecho sin mediadores, de lo que puede ser construido directamente, sin haber sido proyectado, y esto ocurre en la vivienda consolidada, en la que la casa no se concibe en un instante, ni siquiera siguiendo una estrategia, sino que va construyéndose mediante improvisaciones sucesivas que se van enganchando constantemente al presente.

[8] “CCómo transformar una caja?” era, precisamente, el título de la exposición de Cecil Balmond en la bienal de Venecia de 2010 


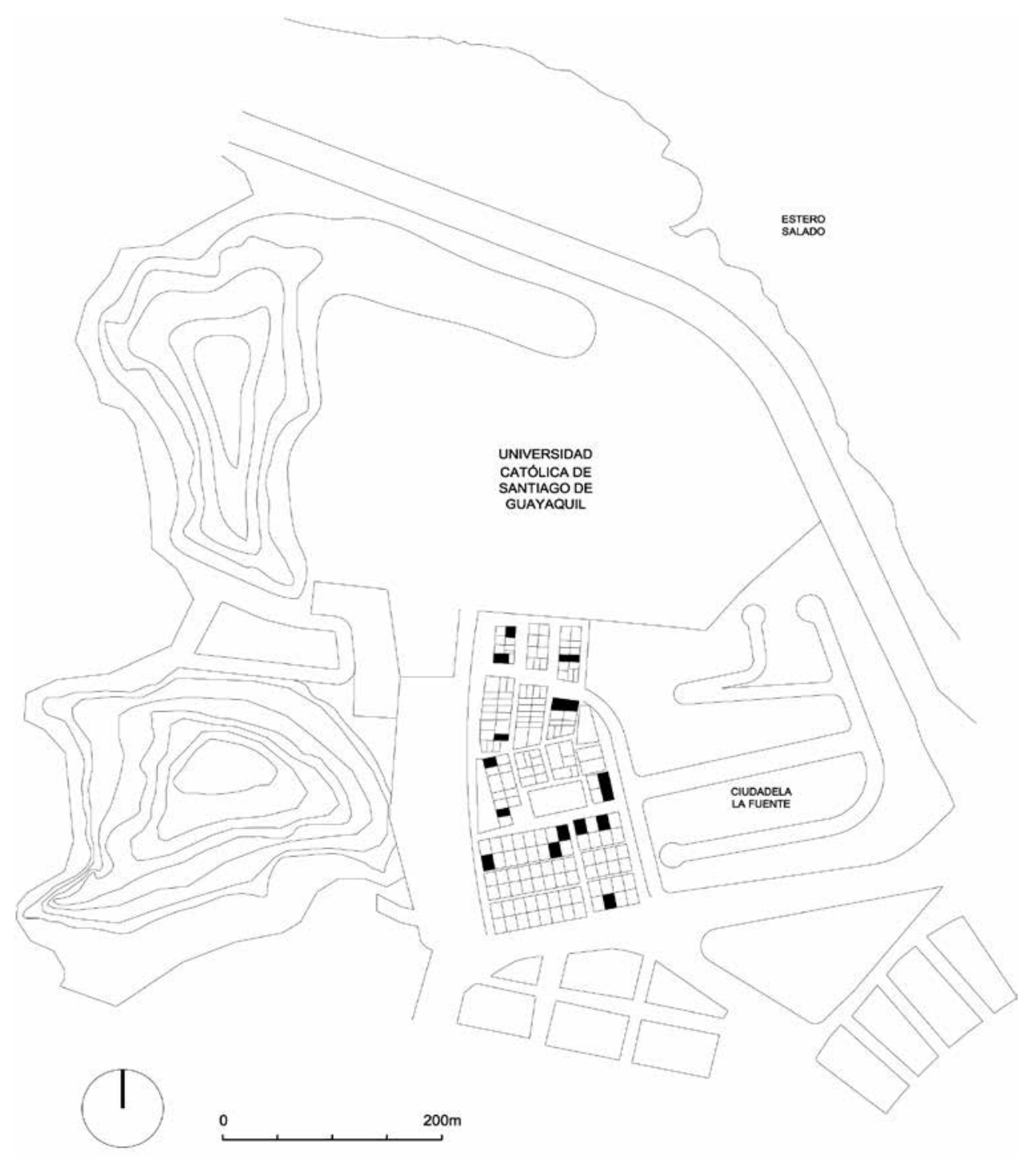

Figura 3 Plano de Santa María de las Lomas, encerrado entre la UCSG al norte, la loma que le da nombre al oeste, una vía principal al sur y la ciudadela cerrada de la fuente al este. Delimitación en negro de las 21 casas escogidas para el análisis de las improvisaciones cualitativas (Tabla 1). Fuente: Elaboración del autor, 2015. 
como reagrupaciones dentro de la familia: $[(1+1)+1+$ $(1+1+1)+1 \ldots$. El desarrollo va asociado al aumento de los miembros de la familia y al alquiler de habitaciones para generar ingresos. La adición de núcleos, genera un aumento exponencial de los intercambios de información en el sistema urbano, porque los nuevos espacios de la casa suman, pero la información se multiplica (Rueda, 1997:167).

Compleción: La estructura inicial de la casa es mayor que su contenido y va llenándose poco a poco. El sistema responde a la serie del tipo: $[1 / n+1 / n+1 / n+1 / n+2 / n$ $+1 /$ n...]. Se crean espacios indefinidos y en espera, que son susceptibles de encontrar nuevos usos no planificados.

División: la casa se fragmenta en respuesta a situaciones de división familiar (divorcio, enemistad entre partes de la familia, reparto hereditario, etc.), escindiéndose en varios núcleos familiares que crecen a partir de entonces autónomamente. El proceso sigue la ecuación: [1 = $1 / 2+1 / 2=1 / 4+1 / 2+1 / 2=1 / 3+1 / 3+1 / 3 \ldots]$.

Sustracción: aunque a escala global ningún barrio de estas características decrece, individualmente cada casa puede hacerlo, siguiendo la serie: $[\mathrm{n}-1-1-1-1-1$ $-1-1 \ldots$. . La eliminación de partes de la casa se debe normalmente a problemas constructivos.

Estas operaciones elementales pueden ser combinadas entre sí, dando lugar a sistemas de cambio complejos, en los que, por ejemplo, una casa es capaz de dividirse en dos y crecer separadamente.

\section{Improvisaciones cualitativas}

Las anteriores transformaciones describen la evolución cuantitativa de la casa y de la familia, mediante relaciones topológicas sencillas entre los núcleos familiares de la casa. Podemos llegar a saber cuántos núcleos familiares hay en una casa, y el desarrollo y la relación entre ellos, pero no cuestiones morfológicas, espaciales, de relación con el espacio público, etc. Para eso estudiamos las improvisaciones cualitativas de la casa, que no nos hablan del tamaño de la misma, sino de la manera en la que se produce la evolución.

Estas improvisaciones generan nuevos caracteres tipológicos que son transferidos horizontalmente dentro del sistema urbano, y que pasan a formar parte del mismo, siguiendo una lógica "lamarckiana" de evolución?. La transformación de la casa no es consecuencia del éxito de mutaciones formales que se adaptan bien al uso, sino que viene fuertemente determinada por el propio uso. Las circunstancias de la familia crean una necesidad, y ésta unos hábitos, los cuales se materializan en nuevos caracteres en la casa, que con el tiempo se fijan en el sistema al copiarse a otras viviendas.

A pesar de la aparente heterogeneidad de un sistema urbano informal como el de Santa María, podemos llegar a reconocer patrones comunes en las viviendas, que nos permiten comparar los caracteres tipológicos entre ellas. El espacio "caja" que identificábamos como germen común a todas las viviendas, puede ser reconocido en la siguiente imagen del barrio (Figura 4), en la

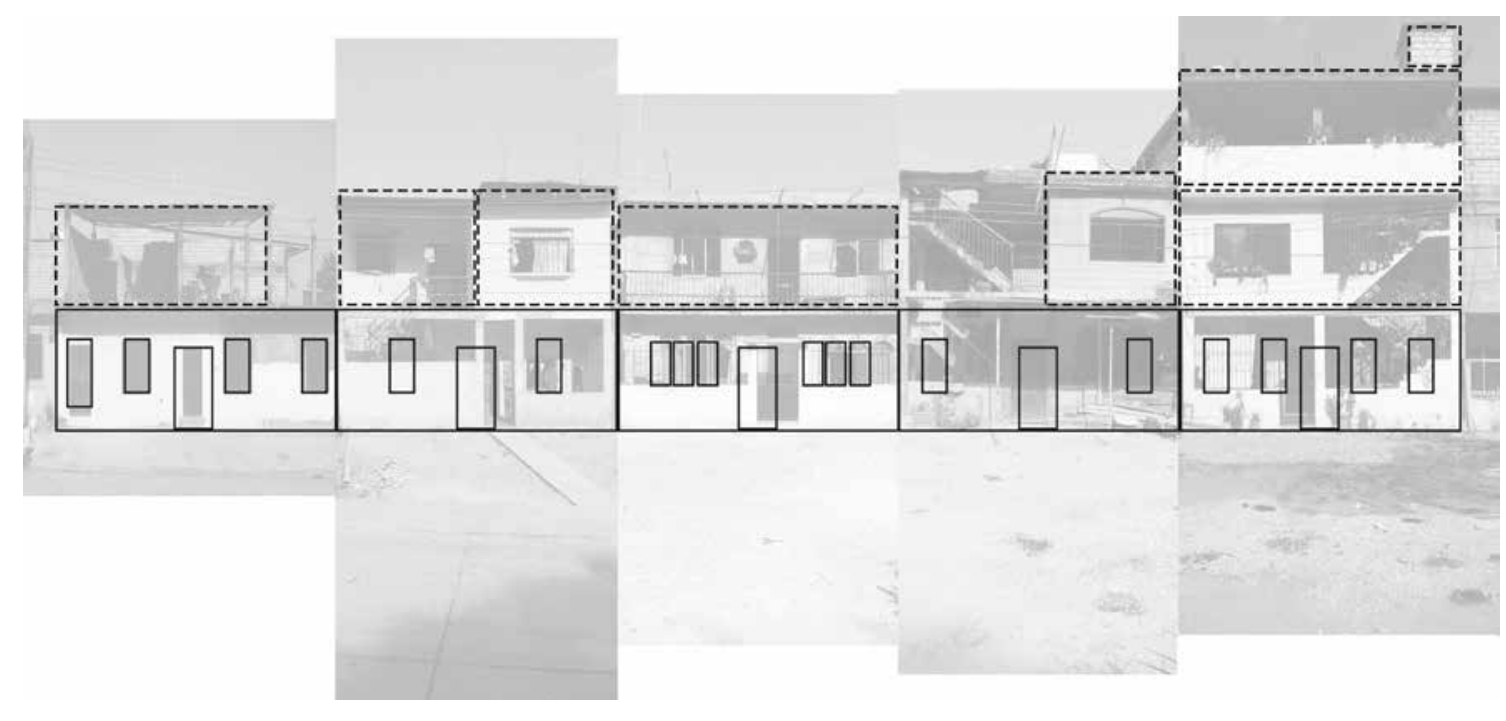

Figura 4 Alzado del barrio desde la loma situada al oeste. Fuente: Elaboración del autor, 2015.

[9] "En los sistemas informales se produce una intensa exploración de lo inmediato" (Balmond, 2002:220), de lo hecho sin mediadores, de lo que puede ser construido directamente, sin haber sido proyectado, y esto ocurre en la vivienda consolidada, en la que la casa no se concibe en un instante, ni siquiera siguiendo una estrategia, sino que va construyéndose mediante improvisaciones sucesivas que se van enganchando constantemente al presente. 

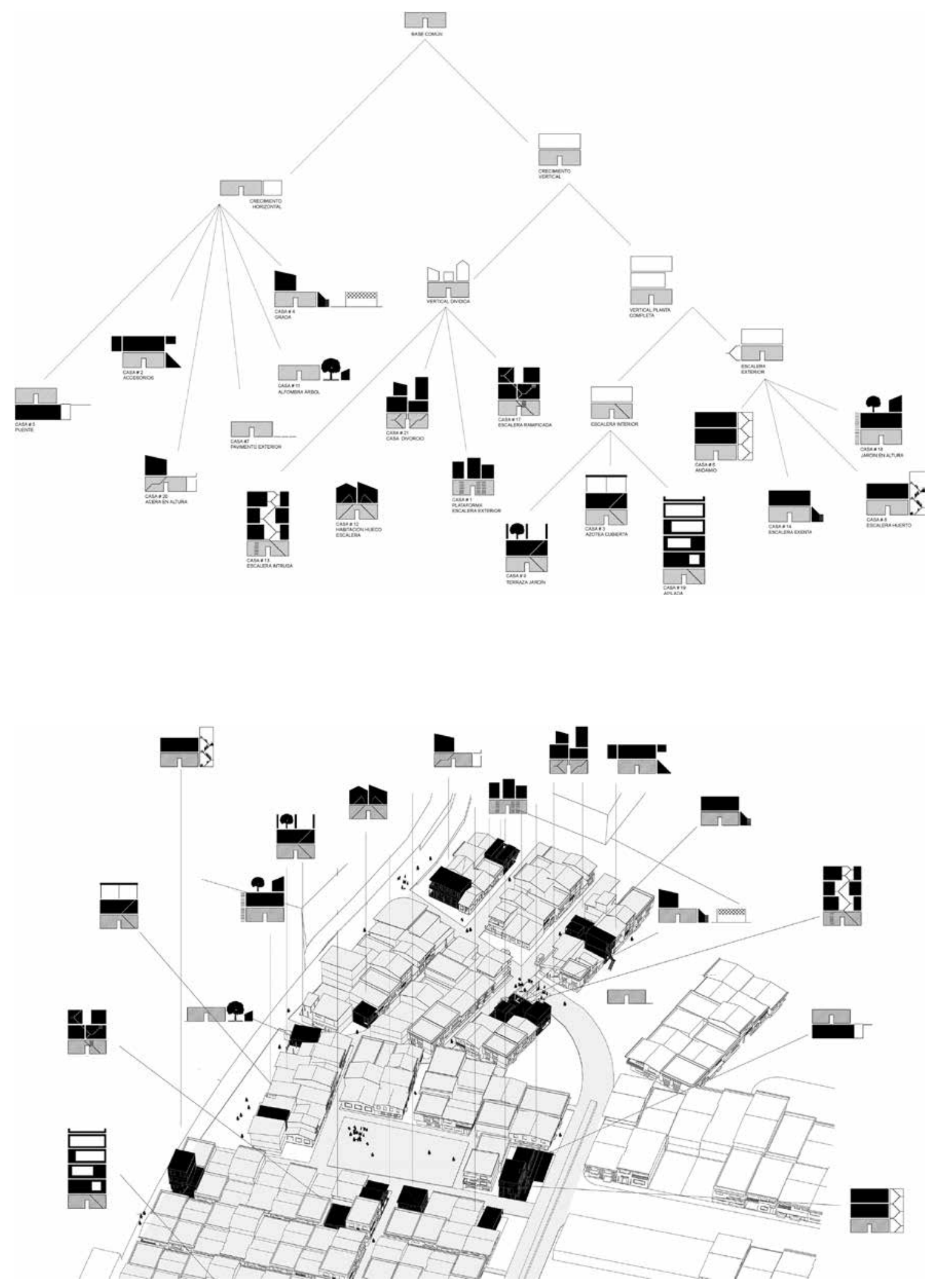

Figura 5 y 6 Caracteres tipológicos de los 21 casos de estudio del barrio de Santa María de las Lomas, en relación a su localización en el barrio, y clasificados siguiendo un esquema genealógico. Fuente: Elaboración del autor, 2015. 
que la primera planta es similar en todas las casas, y el crecimiento posterior varía.

En la investigación se han seleccionado 21 casos de estudio que contienen caracteres tipológicos radicales (Figura 5), que son copiados a otras viviendas. Estos caracteres son mezclados dando lugar a híbridos complejos. Podemos reconocer patrones afines en estas improvisaciones que nos permiten definir, a su vez, familias de caracteres tipológicos, las cuales representan también familias de situaciones domésticas. En el esquema genealógico (Figura 6) las improvisaciones son agrupadas en relación a diversos factores, como su crecimiento vertical u horizontal, la ocupación de la planta entera o la posible división de la misma, o bien, la colocación de la escalera en el exterior o en el interior de la casa.

Estas improvisaciones pueden a su vez ser clasificadas, en relación a su origen, en 3 tipos: mutantes, alienes e híbridos.

Mutante. Se produce mediante alteraciones accidentales y radicales en una tipología, sin la influencia de las casas vecinas, sino a causa de las características excepcionales de las familias. Por ejemplo, cuando una casa tiene poco terreno en planta, pero muchos núcleos familiares, tiende a crecer de manera excepcional en vertical. Se denomina mutación, porque está basada siempre en una tipología existente en el barrio, que se transforma. Esta mutación puede producirse de manera radical (cambios bruscos repentinos) o incremental, mediante pequeñas transformaciones sucesivas ${ }^{10}$.

Alien. El segundo mecanismo se produce, al contrario, no por la variación extraña de un carácter ya existente, sino por la introducción de tipologías foráneas, que a menudo son creadas por la intervención de algún profesional y que, de ser aceptadas, tienen grandes posibilidades de ser extendidas rápidamente dentro del sistema, sustituyendo, e incluso eliminando, muchos de los caracteres locales existentes. Además, su introducción puede causar problemas de exclusión social al sugerir un mayor nivel adquisitivo en las casas en las que aparece.

Híbrido. En este caso, las transformaciones son resultado de la combinación de caracteres tipológicos cercanos, mediante el sistema de copia mejorada o adaptada. Desaparecen las tipológicas claras de vivienda, dando lugar a infinidad de variaciones complejas. No se trata ya de "separar e identificar entidades, sino de descubrir híbridos innombrables" (Koolhaas, 2014:17), porque la arquitectura informal es híbrida por naturaleza"1. Las influencias locales tejen una densa red de interrelaciones en la que cada elemento tiene la capacidad de influir en el comportamiento de los otros, lo que lleva a la aparición de evoluciones convergentes entre las casas.
Estas improvisaciones a escala de casa, se convierten en tanteos a escala de conjunto, en los que aparecen comportamientos globales lógicos.

\section{Tanteos}

Si una de estas unidades complejas de vivienda está aislada en el campo, son limitadas las opciones de cambio que tiene, pero ¿qué pasa cuando se ubica junto a otros núcleos de vivienda? Aparecen entonces intercambios de información entre las familias, dando lugar a un sistema complejo formado por elementos e interacciones, que aumenta exponencialmente las opciones de mutación de la casa. A medida que el sistema urbano crece, aumentan también los contactos e intercambios entre los habitantes, por lo que el sistema se enriquece, y se multiplican las posibilidades de transformación de cada vivienda, produciendo un barrio más flexible y adaptable. $^{12}$

De esta manera, una decisión particular de una casa no tiene por qué representar lo que sucede en el barrio globalmente. Se producen por ello incrementos diferenciales entre las distintas escalas de observación del fenómeno, es decir, entre individuo y familia, entre casa y barrio, etc. Por ejemplo, una casa puede dividirse en varias partes, al mismo tiempo que el barrio, a la inversa, se compacta. Esto hace que los incrementos puntuales a escala de casa no sean necesariamente los mismos que a escala urbana, y que para comprender un cambio en una vivienda sea necesario observar el desarrollo de su entorno cercano.

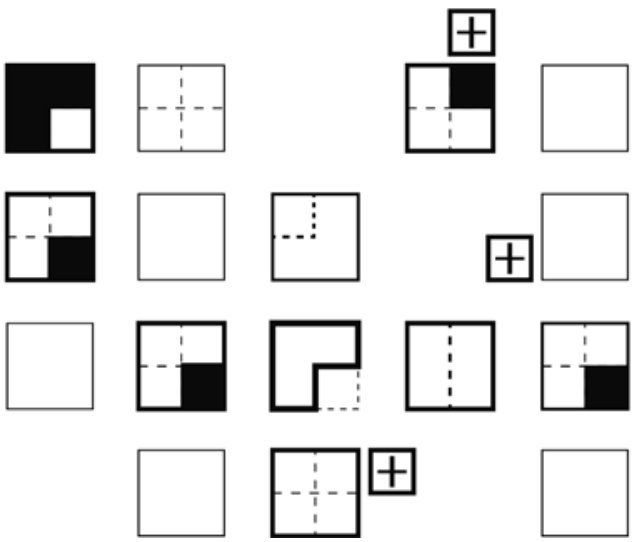

Figura 7 Ejemplo de un sistema complejo de vivienda informal consolidada. Fuente: Elaboración del autor, 2015

[10] D’Arcy Thompson nos habla de los sistemas de transformación en especies biológicas afines, y dibuja diagramas en los que se muestra cómo las nuevas especies son generadas a partir de la acumulación de pequeñas mutaciones en sus predecesores (1961:257-307)

[11] "Los barrios crecen a trochemoche entre de tres a seis variaciones tipológicas de casas vernaculares" (Al, 2014: 50-52)

[12] Salvador Rueda analiza la ciudad como sistema urbano complejo, en el que cuantos más elementos e intercambios de información haya, mayor es su capacidad de adaptación y menor la energía que es necesaria aportar para su desarrollo (1997:154) 
La suma de las modificaciones en un sistema urbano puede ser, de hecho, muy diferente a alguna de las modificaciones en particular, del mismo modo que la acción de levantarse de una persona dentro de una ola humana en un estadio de futbol es diferente al desplazamiento de la propia ola ${ }^{13}$.

Entendiendo esto, se hace necesario observar el barrio como sistema multi-escalar, en el que "nuestra habilidad para cambiar la escala de observación del fenómeno nos permitirá poder ver el mismo objeto-sujeto como singular y plural al mismo tiempo, lo que convierte el habitual problema de cómo objetualizar la arquitectura, en una cuestión de escala de interpretación" (Willensky y Resnick, 1999:25).

\section{Tanteos cuantitativos}

En el siguiente esquema (Figura 8), se recoge la evolución de todas las viviendas del barrio estudiado, a través de tres periodos separados 20 años entre sí (1975, 1995 y 2015). El sistema de análisis que se muestra permite entender el barrio como conjunto, y como suma de individualidades al mismo tiempo, abriendo el camino para un posterior análisis en profundidad de las implicaciones de este cambio en la escala de observación. En dicha figura se observa que surgen focos de crecimiento, en los que las casas parecen ponerse inconscientemente de acuerdo para densificarse en el borde con una calle concurrida, o para crear un espacio colectivo junto al parque. La transformación de cada vivienda por separado genera, de esta forma, movimientos grupales intuitivos, por lo que los hábitos domésticos a escala de casa dan lugar, a escala de barrio, a reacciones lógicas más parecidas a los instintos que a dichos hábitos. Mientras que la casa está aparentemente atascada en lo cotidiano, el barrio se llena de intenciones en su transformación.

\section{Tanteos cualitativos}

Algo similar a esto parece ocurrir si analizamos a escala de conjunto las improvisaciones cualitativas llevadas a cabo por cada casa. En la imagen (Figura 9), se ha representado de manera ficticia cómo el modo de crecer de las casas por separado, adquiere comportamientos lógicos si se lo observa grupalmente. De esta forma, se pueden llegar a crear gradas y tiendas de venta de comida junto a las canchas deportivas dibujadas en la calle, dando lugar a estadios improvisados, o a parques comunes derivados de la plantación de árboles por varias casas de la misma zona. De esta forma, el barrio puede ser capaz de producir zonas comunes, que no han sido planificadas, sino originadas por el barrio como sistema emergente.

En ambas imágenes se pueden identificar los puntos desde los que parte el desarrollo de cada casa, estructurando la densificación del barrio a través de determinados focos de crecimiento. Estos focos están asociados cada uno de ellos a una familia inicial, que va añadiendo nuevos núcleos familiares con el tiempo. Cada foco es, asimismo, una casa colectiva en la que varios núcleos familiares comparten una misma casa, creándose identidades supra-familiares susceptibles de relacionarse entre sí. La transformación del barrio va, por tanto, estrechamente unida a la relación existente entre casa y familia, por lo que, a continuación, se analizan los movimientos de aproximación que aparecen entre ambos.

\section{Aproximaciones $^{14}$}

En la ciudad formal, la familia tradicional habita casas tradicionales donde se produce una doble limitación: la casa no permite estructuras familiares complejas ya que resulta difícil, por ejemplo, aumentar una planta y construirle un nuevo acceso independiente a la familia de los hijos, y, por otro lado, la familia no requiere grandes esfuerzos por parte de la casa puesto que se fragmenta y traslada rápidamente, desligándose de la casa original. La casa y la familia restringen conjuntamente las posibilidades de generación de estructuras colectivas más complejas; estructuras que son deseables para la ciudad porque establecen nuevos círculos de identidad colectiva.

Si analizamos lo que ocurre en la vivienda informal consolidada, podemos detectar movimientos de aproximación entre la casa y la familia. Existe una influencia bilateral entre ambas, creada por pequeños cambios acumulativos que hacen que el desarrollo de la casa y el de la familia se produzcan de la mano y en el tiempo, dando lugar a las estructuras colectivas complejas que demanda la ciudad. El detonante de cambio no es aquí ni la arquitectura, ni la sociedad, sino la relación dialéctica entre ambas.

[13] En el ejemplo de la ola humana, existen movimientos diferenciales entre la ola y cada persona, y si observamos sólo a escala de persona cómo alguien se levanta, no lo entenderemos, pero se generará un fenómeno global con sentido que sólo puede ser identificado desde una observación a mayor escala. El conjunto de decisiones individuales de cada persona al levantarse de la silla, es la que forma el comportamiento global ordenado. No hay una persona que dirija todo este movimiento, sino que cada uno reacciona a los estímulos de las personas de al lado cuando la ola está llegando a él. En su artículo "Thinking in levels", Willensky y Resnick (1999) añaden al de la ola humana varios ejemplos más de movimientos diferenciales en relación a la escala de observación del fenómeno. Estos ejemplos ayudan a comprender la importancia del cambio de escala de observación en el estudio de los sistemas urbanos [14] Alejandro Aravena (reconocido arquitecto chileno, ganador del premio Pritzker en el 2016), cuenta cómo algunos utensilios y herramientas hechos por el hombre mediante modificaciones y cambios sucesivos a lo largo de siglos, poseen una condición natura que los aleja del artificio. La "arquitectura por aproximación", como el la denomina, puede llegar a tener esta condición. La casa no se concibe en un instante, sino que va construyéndose por tanteos sucesivos que se van actualizando constantemente. Aproximaciones incrementales entre casa y usuario que quieren ser la misma cosa. Esta suerte de naturalidad es probablemente la máxima aspiración de la arquitectura doméstica. (Entrevista realizada por: Pacho O'donnell en el programa "La belleza de pensar". 2 de octubre de 2015 Disponible en: https://www.youtube.com/watch?v=6ZfOR9HTLp8 


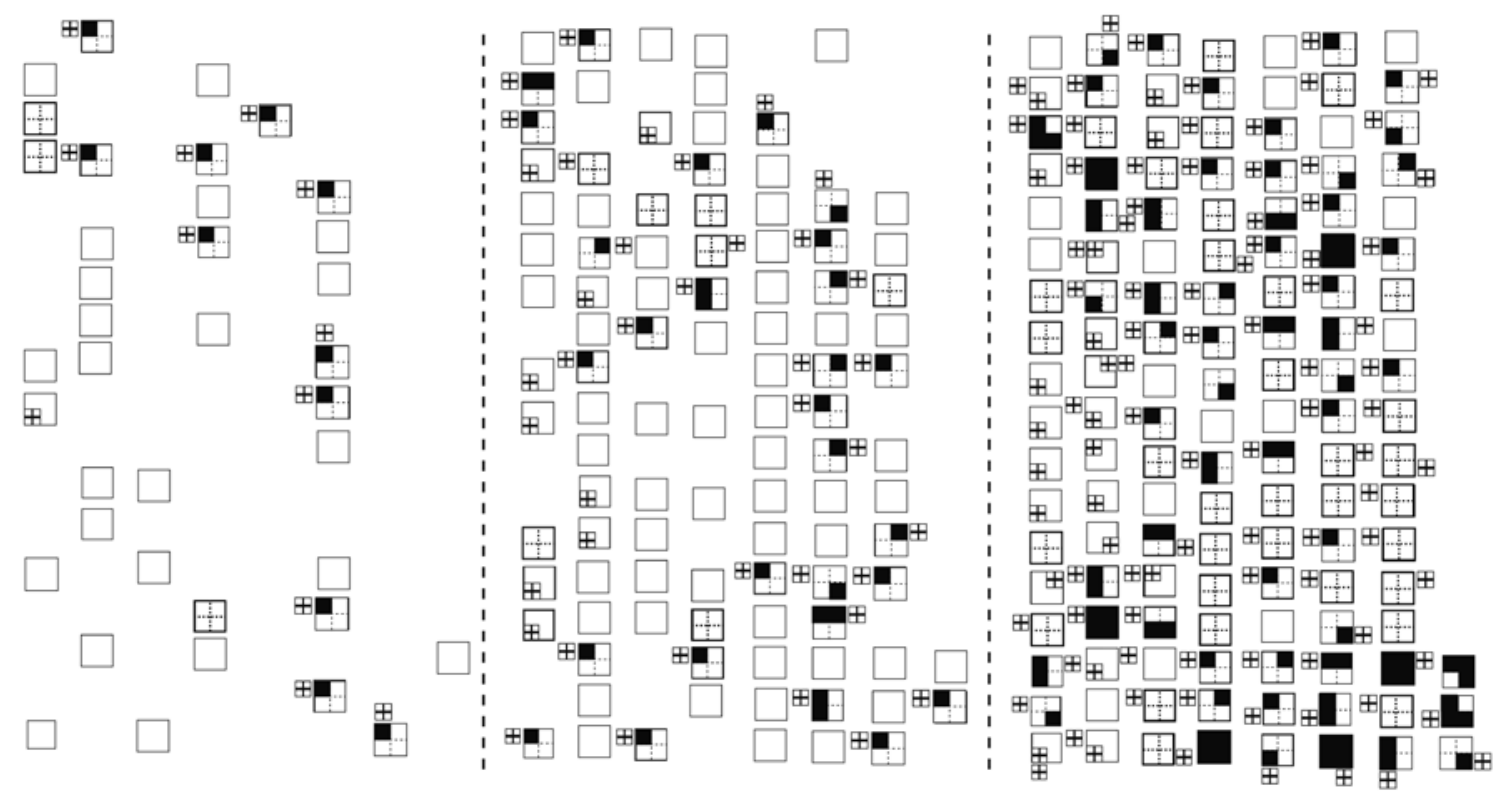

Figura 8 lncremento de núcleos familiares en el barrio de Santa María de las Lomas en tres periodos sucesivos: 1975 , 1995 y 2015 . Fuente: Elaboración del autor con colaboración de Katherine Urgilés, 2016.

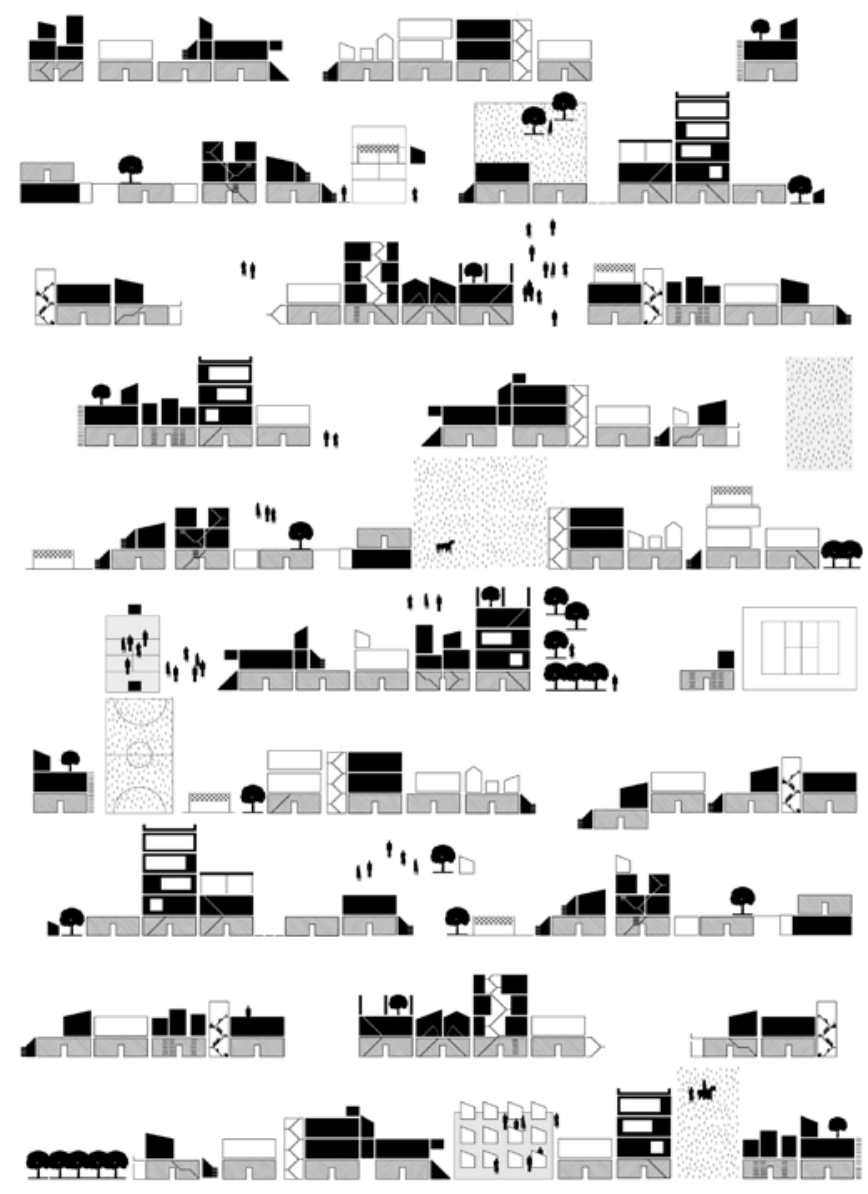

Figura 9 Transformación mediante "tanteos sucesivos" en un sistema de vivienda informal consolidada. Fuente: Elaboración del autor, 2015. 


\section{Aproximaciones cualitativas}

En el siguiente diagrama (Figura 10), se analiza la relación de algunas de las improvisaciones cualitativas detectadas anteriormente, con las familias que las ocupan. La primera columna muestra estas improvisaciones y las siguientes columnas, la estructura familiar, representada mediante tres esquemas: el primero muestra la estructura familiar, mediante $(\mathrm{x})$ para los miembros masculinos, y (o) para los miembros femeninos de la familia. El segundo diagrama representa, mediante círculos, los núcleos familiares creados, y el tercero muestra el diagrama sintético que se ha utilizado para el análisis de aquí en adelante.

De este modo, la primera fila (1) representa una estructura familiar caracterizada por el divorcio de los padres, en la que se dividen en dos los núcleos familiares, los cuales siguen viviendo en la misma casa, creciendo separadamente hacia arriba. En este caso, ambos núcleos tienen la misma importancia en la casa, por lo que conservan el contacto con el terreno. En la segunda fila (2), la casa se caracteriza por tener una primera planta que sirve de plataforma para nuevos núcleos familiares que se sitúan encima. La familia se compone del núcleo principal de los padres y de los núcleos generados por los hijos con sus respectivas familias. Sólo los padres tienen contacto con el terreno. En el tercer ejemplo (3), la familia de la hija (con acceso independiente) crece más que la de los padres, por lo que requiere ampliarse, haciéndolo hacia los costados en lugar de hacia arriba para ahorrar dinero, aprovechando que no hay más núcleos. En el último caso (4), en cambio, hay varios núcleos familiares formados por los hijos de la primera familia, que tienen la misma importancia, por lo que se crea una escalera exterior para evitar la dependencia que generaría la escalera interior para los pisos superiores. Esto permite también alquilar habitaciones para generar ingresos.

\section{Aproximaciones cuantitativas}

Igualmente, es posible analizar la relación de las operaciones de adición, compleción o división con las estructuras familiares con las que van asociadas. En los diagramas siguientes (Figura 11), se expone, en primer lugar, un cuadrado sencillo que representa una vivienda no evolutiva, asociada a una familia de estructura sencilla compuesta por padres e hijos. A continuación, el segundo y tercer diagrama, de adición de nuevos núcleos y de compleción de la estructura de la casa, van asociados a estructuras familiares en las que los hijos o primos son capaces de arraigarse con sus propias familias en la casa de los padres, junto a la posibilidad también de alquilar habitaciones para generar ingresos. El cuarto diagrama, de división, va asociado a una familia capaz de escindirse en varios núcleos, como sucedía en el anterior caso de divorcio. Como último ejemplo, se muestra un diagrama en el que se superponen varias de estas operaciones aritméticas y se dibuja al lado una estructura familiar compleja en la que la familia al igual que la casa, es capaz de fragmentarse e incorporar nuevos núcleos dentro de la estructura inicial de la casa, y como adiciones exteriores.

\section{CONCLUSIONES}

Aunque la clasificación previamente expuesta puede ser entendida, en cierto modo, como una conclusión en sí misma, aparecen reflexiones globales a partir de la dialéctica entre las improvisaciones, tanteos y aproximaciones, susceptibles de ser resumidas en los siguientes puntos.

\section{Improvisaciones vs tanteos: sistema fractal y primeras vecindades}

Si comparamos las transformaciones del barrio casa por casa (improvisaciones) y como conjunto (tanteos), podemos identificar sistemas arquitectónicos y de organización social semejantes en ambas escalas ${ }^{15}$.

En el gráfico (Figura 12), se compara la estructura social del barrio, con la producida en una ciudadela formal de viviendas unifamiliares. El esquema convencional de la derecha produce familias similares e incomunicadas, mientras que en el de la izquierda se crean estructuras familiares complejas y diversas, que se comunican entre sí. Aparecen, de esta manera, encuentros e intercambios de información dentro de la propia estructura familiar, en el seno de estructuras supra-familiares derivadas del encuentro entre vecinos cercanos. Estas primeras vecindades (representadas en línea discontinua) son imprescindibles para la posible generación de comportamientos globales lógicos a partir de decisiones individuales tomadas por cada casa, y dan lugar a una sintaxis familiar compleja, y fractal ${ }^{16}$.

[15] “La ciudad Genérica es fractal, una interminable repetición del mismo módulo estructural simple; es posible reconstruirla a partir de la pieza más pequeña como, por ejemplo, un ordenador de sobremesa, tal vez incluso un disquete" (Koolhaas, $2014: 44$. [16] Podemos entender la estructura social del barrio como un conjunto de partes que se relacionan entre sí a modo de sintaxis familiar, en la que se dan dos tipos de esquemas bien diferenciados: el yuxtapuesto (u orden paratáctico), de las ciudadelas formales, en las que se colocan las familias una junto a otra sin relación directa, y el esquema subordinado (o hipotáctico), en el que se forman estructuras inclusivas. En este segundo esquema, representado en la Figura 13 a la izquierda, cada familia forma parte de una estructura familiar mayor. 


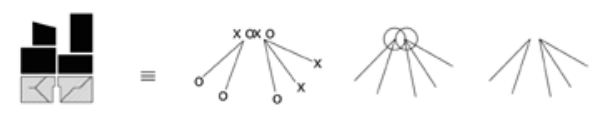

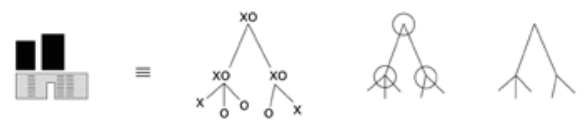

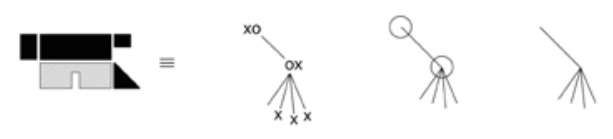

E

Figura 10 Aproximaciones cualitativas entre casa y familia, en cuatro de los caracteres tipológicos analizados. Fuente: Elaboración del autor, 2016.

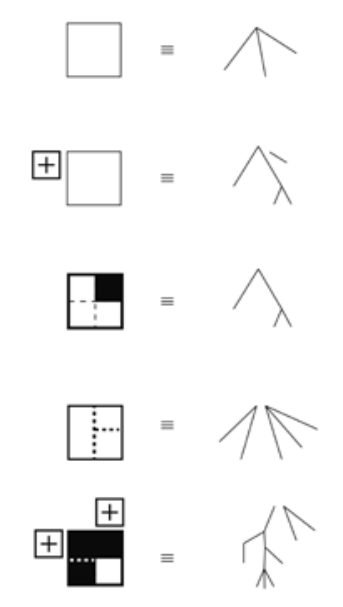

Figura 11 Aproximaciones cuantitativas entre casa y familia Fuente: Elaboración del autor, 2016.

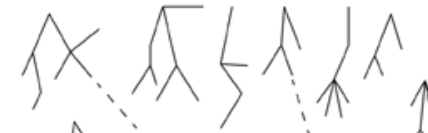

$$
\begin{aligned}
& M \lambda_{\lambda} \lambda^{-}-\lambda \lambda \lambda^{\wedge} \lambda^{\lambda} \\
& \left.\Delta \lambda_{\lambda} \lambda{ }^{\lambda} \lambda_{-\prime}^{\prime \prime \lambda}\right\rangle \\
& \hat{b}\left\langle\lambda \lambda \lambda_{\lambda} \hat{\lambda}\right.
\end{aligned}
$$

$\wedge \wedge \wedge \wedge \wedge \wedge \wedge \wedge \wedge$

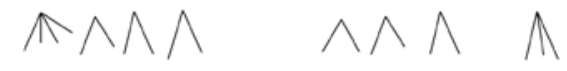
$\wedge \wedge \wedge \wedge \mathbb{\wedge} \wedge \wedge \wedge \wedge$ $\wedge \wedge \wedge \wedge \wedge \wedge \wedge \wedge \wedge \wedge$ $\wedge \wedge \wedge \wedge \wedge \wedge \wedge \wedge \wedge$

Figura 12 Diagrama comparativo de la estructura familiar de un barrio informal con la aparición de primeras vecindades (izq.) y la estructura de un barrio formal (dcha.). Fuente: Elaboración del autor, 2015.

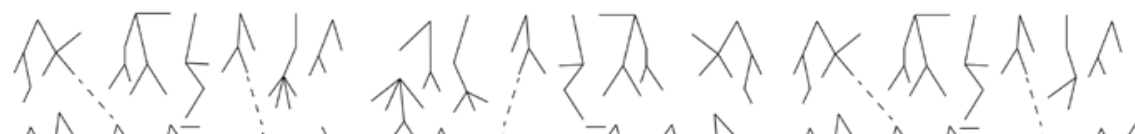

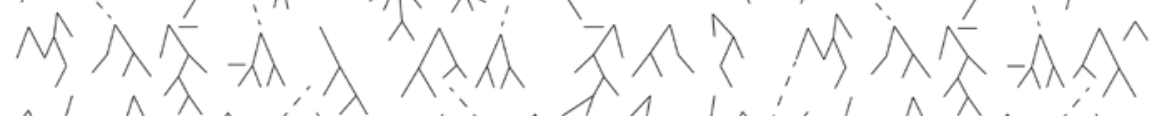

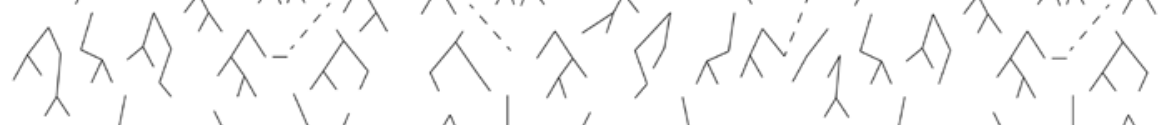

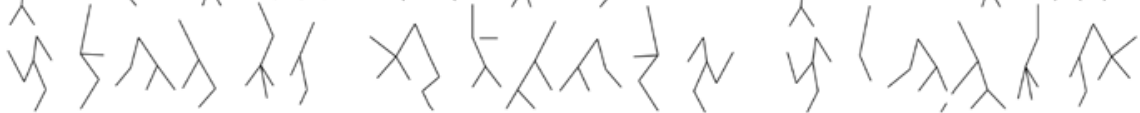

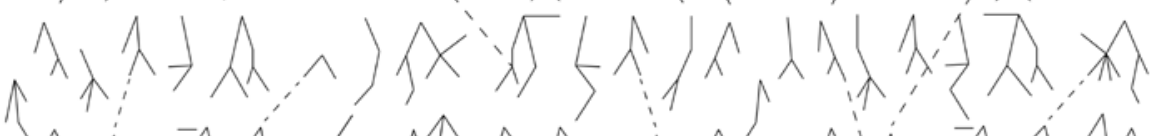

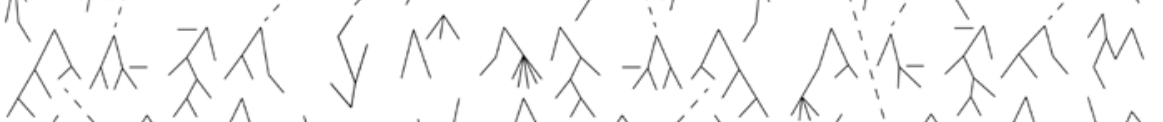

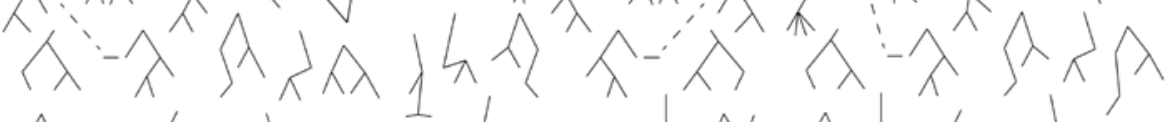

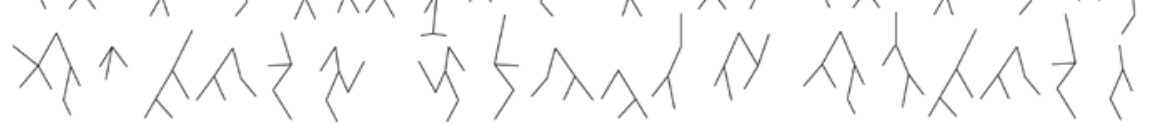

Figura 13 Recreación de la estructura fractal del barrio, en la que se pueden identificar las mismas estructuras sociales a varias escalas diferentes, creándose grupos inclusivos de identidad que aportan cohesión al barrio. Fuente: Elaboración del autor, 2015. 


\section{Improvisaciones vs aproximaciones: hibridación espacial y social}

Como se puede ver en los diagramas de aproximación entre casa y familia (Figuras 10 y 11), ambas entidades necesitan la participación conjunta para formar un verdadero motor de cambio social. El desarrollo en paralelo de la casa y de la familia conlleva, a su vez, una libertad de transformación que tiende a eliminar los estereotipos formales y sociales. Tanto en la familia como en la casa desaparecen las tipologías sencillas para dar lugar a híbridos complejos. A medida que las casas van acumulando varios caracteres tipológicos distintos, las familias abandonan el esquema convencional de padres e hijos, para generar estructuras enmarañadas en las que se incorporan nuevos núcleos familiares de dentro y fuera de la familia, y en donde el habitar se mezcla con otros usos con el objetivo de generar ingresos (familiahotel, familia-restaurante, etc.).

\section{Tanteos vs aproximaciones: colectividad progresiva}

Si hacemos esta misma comparación con los tanteos producidos a escala urbana, al poner en paralelo la transformación del barrio y de la comunidad (Figuras 8 , 9 y 14), se pueden reconocer agrupaciones intermedias, que dan lugar a nuevas escalas de colectividad dentro del barrio. La aparición de estas agrupaciones no es planeada, sino que surge con el paso del tiempo gracias a las primeras vecindades y a la capacidad de las viviendas de transformarse para construir espacios colectivos. La colectividad, por tanto, no es diseñada en un comienzo, sino que se genera de manera natural a medida que van apareciendo acuerdos inconscientes entre familias, por lo que surge en escalas intermedias en las que no suele producirse. Se genera por tanto una colectividad progresiva a diferentes escalas.

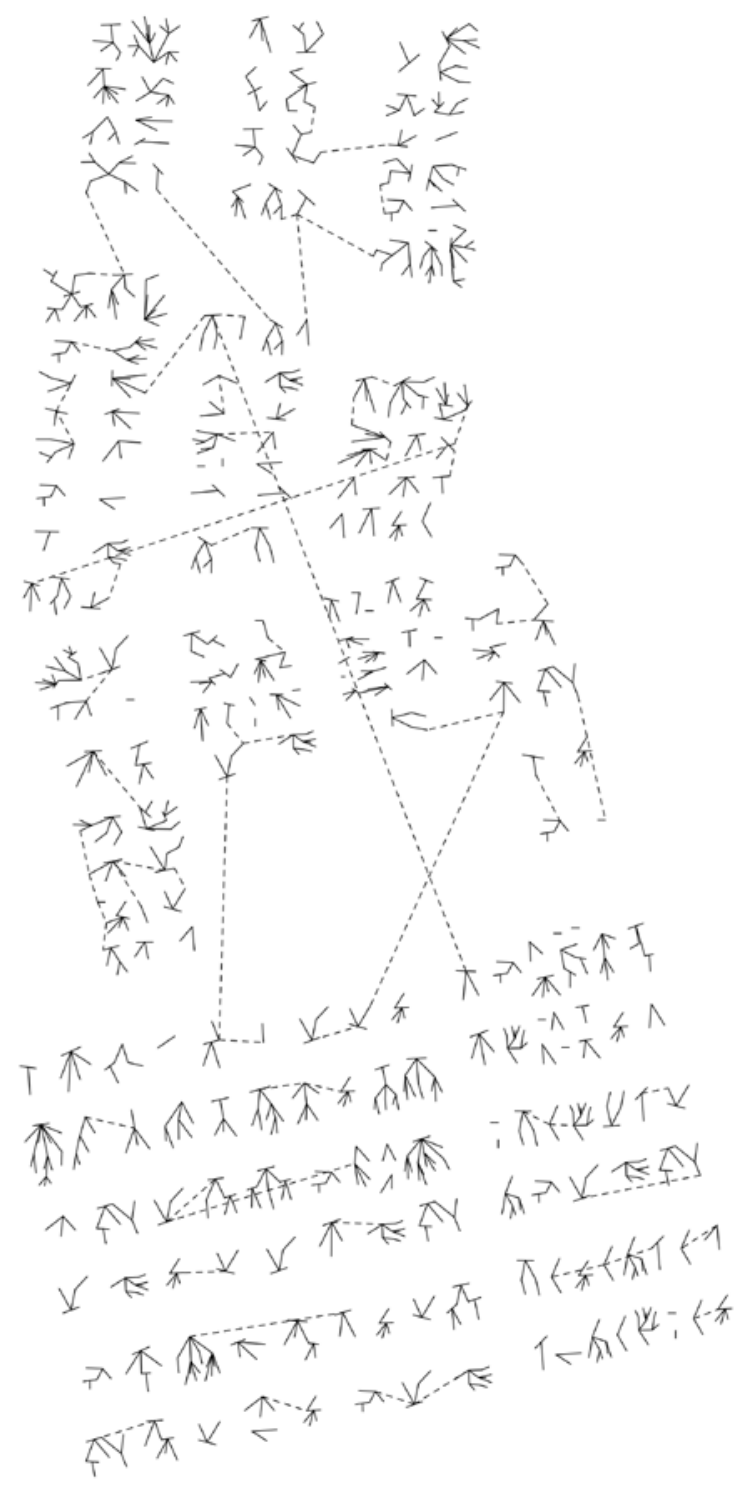

Figura 14 Planta del barrio con las estructuras familiares de cada casa colocadas sobre su parcela, y las conexiones sociales entre familias representadas con línea discontinua. Fuente: Elaboración del autor con colaboración de Sofía Plaza, 2016. 
AL, Stefan. Villages in the City: a Guide to South China's Informal Settlements. $1^{\text {a }}$ edición. Hong Kong: Paramount Printing Co., 2014

BALMOND, Cecil. Informal. Londres: Prestel Publishing, 2002.

DARWIN, Charles. El origen de las especies. Lima: Fondo Editorial de la Cultura Peruana, 2012.

DE TERESA, Ignacio. Relación entre las características tipológicas funcionales de la vivienda unifamiliar informal y su evolución espacial. Guayaquil: SINDE, 2015.

JOHNSON, Steven. Sistemas emergentes o qué tienen en común las hormigas, las ciudades y el software. México D.F.: Fondo de Cultura Económica, 2003.

KOOLHAAS, Rem. Acerca de la ciudad. Barcelona: GG, 2014.

LAMARCK, Jean Baptiste. Filosofía zoológica. Barcelona: editorial Alta Fulla, 1986.

MOSER, Caroline. Gente de barrio, vidas extraordinarias: activos y reducción de la pobreza en Guayaquil, 1978-2004. Santiago de Chile: Ediciones SUR, 2010.

RUEDA, Salvador. La ciudad compacta y diversa frente a la conurbación difusa. En: GARCÍA-GERMAN, Javier, De lo mecánico a lo termodinámico, por una definición energética de la arquitectura y del territorio. Barcelona: GG, 1997, pp. 153-170.

THOMPSON, D'Arcy. Sobre el crecimiento y la forma. $16^{\mathrm{a}}$ edición. Madrid: Ediciones Akal, 1961.

WILLENSKY, Uri y RESNICK, Mitchel. Thinking in Levels: a Dynamic Systems Approach to Making Sense of the World. Journal of Science Education and Technology, 1999, vol. 8, n 1, pp. 3-19.

ZULOARK. El futuro no es futurible. De pequeños creíamos que era cuestión de esperar. Revista Circo [en línea], 2009, n 156, pp. 5. [Consultado 30 mayo de 2016]. Disponible en: http://www.mansilla-tunon.com/circo/ epoca7/pdf/2009_156.pdf 